\title{
Anterior decompressive surgery for cervical ossified posterior longitudinal ligament causing myeloradiculopathy
}

\author{
H Baba, ${ }^{1}$ N Furusawa, ${ }^{1} \mathrm{Q}$ Chen,${ }^{1}$ S Imura,${ }^{1} \mathrm{~K}$ Tomita ${ }^{2}$ \\ ${ }^{1}$ Department of Orthopaedic Surgery, Fukui Medical School, Matsuoka, 23 Shimoaizuki, Fukui 910-11, Japan; \\ ${ }^{2}$ Department of Orthopaedic Surgery, Kanazawa University School of Medicine, Kanazawa 920, Japan
}

\begin{abstract}
This paper reviews 88 patients (74 males and 14 females) who underwent anterior decompression and fusion for symptomatic ossified posterior longitudinal ligament of the cervical spine. Follow up averaged 8.5 years. Eighteen patients underwent one-vertebra, 59 two-vertebra, and 11 three-vertebra decompression with interbody fusion. The preoperative severity of symptoms significantly affected neurological recovery. Patients with three-vertebra spondylectomy showed significantly little neurological improvement. The return of patients to their previous activities as monitored at follow up was related to their preoperative neurological status. MRI findings appeared to be relevant to neurological recovery. Our findings suggest that anterior decompression is to be recommended for patients with less advanced preoperative symptoms and the involvement of one or two vertebrae.
\end{abstract}

Keywords: anterior decompression; cervical spine; ossification of the posterior longitudinal ligament; myeloradiculopathy; magnetic resonance imaging

\begin{abstract}
Introduction
Symptoms secondary to ossification of the posterior longitudinal ligament (OPLL) of the cervical spine vary, ${ }^{1-12}$ and patients whose symptoms progress require OPLL resection through an anterior cervical fusion (ACF) or a posterior decompression, or occasionally both. The procedure to be used has been discussed, ${ }^{13-17}$ but the choice should be based on the advantages and disadvantages for the individual patient. OPLL resection using ACF effectively relieves neurological symptoms, but the patient's overall condition may worsen despite carrying out this procedure. Due to questions about the factors affecting surgical timing and adequacy, a long term follow up study was made of patients who had undergone ACF for cervical OPLL, and its surgical advantages over other reported operated results are discussed.
\end{abstract}

\section{Patients and methods}

\section{Patients and diagnostic issues}

Between 1977 and 1992, 114 patients with symptomatic cervical OPLL underwent ACF at Fukui Medical School and the Kanazawa University School of Medicine. Of these, 24 were excluded from this study: nine had changed their residence or refused reexamination, eight had died, four had pseudoarthrosis, and three were ineligible due to other coexisting neurological disease. The remaining 88 (74 men and 14 women)

This paper was presented at the 33rd Annual Scientific Meeting of the International Medical Society of Paraplegia, May 31-June 2 1994, Kobe, Japan. were studied with a minimum 2-year follow up ranging from 2 to 14 years and averaging 8.5. The patients were aged 34 to 73 , and averaged 47 years of age at the time of surgery. The history ranged from 0.2 to 12 years, averaging 2.4 years. None had any major presurgical traumatic spinal cord injury associated with cervical OPLL. ACF was not indicated for subjects with complete spinal cord injury due to OPLL. All ACF was performed by one or two of the authors (HB and/or $\mathrm{KT}$ ), using the same surgical technique; neurological results were assessed by two others (NF and QC) at final follow up.

Indications for ACF were distinct evidence of symptoms and signs of myeloradiculopathy secondary to cervical OPLL. We used the Japanese Orthopaedic Association (JOA) scoring system for cervical myelopathy in neurological assessment (Table $\mathrm{I})^{18}$ and results were evaluated by the neurological improvement rate determined as follows: (postoperative score - preoperative score $) /(17$ - preoperative score $) \times 100 \%$. Patients were placed before surgery into one of three groups: severe (group A, JOA score $\leqslant 5$ points), moderate (group B, JOA score 6-12 points), or mild (group C, JOA score $\geqslant 13$ points). The postsurgical neurological status was classifed as excellent (improvement rate $\geqslant 75 \%)$, good $(50-74 \%)$, fair $(25-49 \%)$, or poor $(\leqslant 24 \%)$. Daily activities were assessed based on criteria (Table II) that we modified and simplifed from those described by Harsh et al: ${ }^{19}$ completely dependent on others (grade 1), severely impaired (grade 2), moderately impaired (grade 3), minimally impaired (grade 4), or not functionally impaired (grade 5).

OPLL radiology routinely involved plain lateral radiography, tomography, and computed tomography 
Table I The Japanese Orthopaedic Association scoring system for assessment of cervical myelopathy. ${ }^{18}$ Neurologically normal condition is a total of the best score: $(\mathrm{I}+\mathrm{II}+\mathrm{III}+\mathrm{IV})=17$ points

\begin{tabular}{ll}
\hline Categories & Score \\
\hline 1 Motor function in the upper extremities & \\
Unable to eat with either chopsticks or a & 0 \\
$\quad$ spoon & 1 \\
Able to eat with a spoon, but not chopsticks & 2 \\
Able to eat with chopsticks, but inadequately & 3 \\
Able to eat with chopsticks, but awkwardly & 4 \\
Normal & \\
2 Motor function in the lower extremities & 0 \\
Unable to walk & 1 \\
Needs cane or aid on flat ground & 2 \\
Needs aid only on stairs & 3 \\
Able to walk unaided, but slowly & 4 \\
Normal & \\
3 Sensory function & \\
(a) Upper extremities & 0 \\
$\quad$ Apparent sensory disturbance & 1 \\
$\quad$ Minimal sensory disturbance & 2 \\
Normal & \\
(b) Lower extremities & 0 \\
$\quad$ Apparent sensory disturbance & 1 \\
Minimal sensory disturbance & 2 \\
Normal & 0 \\
(c) Arunk & 2 \\
Mpparent sensory disturbance & 1 \\
Normal sensory disturbance & \\
Urinary retention or incontinence & \\
Severe dysuria (sense of retention) & \\
Nlight dysuria (pollakiuria, retardation) & \\
Normal & \\
\hline
\end{tabular}

Table II Daily living levels

Grade 1 Totally dependent on others; wheelchairdependent, standing difficult, bed transfer not possible, grooming/1dressing not possible

Grade 2 Severely impaired; ambulatory only in house and always aided, stairs not possible, grooming/dressing needs assistance, bed/toilet transfer needs some assistance

Grade 3 Moderately impaired; one-cane walking possible but not running, can use public transportation unassisted, light work possible, personal hygienic care with minimal assistance, can enjoy a walk

Grade 4 Minimally impaired; driving possible, ambulatory completely unaided, personal care independent, able to enjoy light sports, no restrictions in ordinal job

Grade 5 No functional impairment; no difficulty in personal care or job, able to enjoy most social events and recreational sports myelography (GE CT/T 8800, General Electric, Milwaukee, WI, USA). Magnetic resonance imaging (MRI) was carried out for some patients, using a GE 1.5 Tesla Signa System (General Electric, Milwaukee, WI, USA) with a standard surface coil. At levels suspected to be responsible for surgically treated myelopathy in 24 patients followed up from 2 to 6.3 years for an average of 3.5 years, MRI spine-echos image were assessed before surgery and at final follow up. Signal changes in T1-weighted MRI (TR $600 \mathrm{ms,}$ TE $120 \mathrm{~ms}$ ) were classifed as normal, slightly high, very high, or cyst-formative. To examine the relationship between changes in the MRI signal at the latest follow up and spinal canal compromise, the preoperative stenosis ratio (\%) in a lateral radiograph was determined in each patient as the anteroposterior diameter of the OPLL to the diameter of the spinal canal in the sagittal plane and expressed as a mean \pm standard deviation. In addition, other factors affecting changes in the MRI signal, such as the duration of the disease, follow up and the levels of decompression and fusion, were analyzed. A $\chi^{2}$ test was used for the neurological examination and Student's $t$ test for MRI assessment, with $p<0.05$ viewed as being significant.

\section{Anterior decompression and cervical fusion}

A standard left-side anterolateral approach was used for all of the patients. Portions anterior to the involved vertebrae were resected in the usual way together with the intervertebral discs: and the posterior cortices were thinly shaved, an operating microscope often being used (OPM 16CFC, Carl-Zeiss, Germany). Then the nonossified portions of the posterior longitudinal ligament were exposed laterally, cranially, and distally. Most OPLL lesions develop medially to centrolaterally. ${ }^{20,21}$ Thus, the lateral portions of the ligament are adequate and safe in reaching the anterior epidural space followed by exposure of the dura mater; vertebra resection $1.5 \mathrm{~cm}$ wide is usually sufficient (Fig 1 ). The proximal and distal ends of the OPLL lesion are then identified, followed by exposure of the dura mater; thus the lesion is isolated and 'floats' on the dura mater. With a microsurgical technique, the OPLL lesion was slightly suspended anteriorly with a fine-tipped hook and nonossifed portions of the ligament were removed with a micro-Kerrison rongeur (Eagle, Tokyo, Japan, or Aesculap, Tuttlingen, Germany). Because the posterior margin of the OPLL lesion may adhere slightly to the dura mater, blunt dissection pulling the lesion anteriorly with a microraspatorium (Aesculap, Tuttlingen, Germany) is required. In most cases, however, the OPLL lesion was removed easily if the lateral and longitudinal parts of nonossified portions of the posterior longitudinal ligament were resected. Then, using a high-speed steel burr, anchor holes are made in the centre of the ends of the cranial and caudal vertebrae; the use of a diamond burr should be avoided because it produces heat injury in the cancerous graft beds that may lead to a possible risk in the delay of bony union. Holes about $10 \mathrm{~mm}$ in diameter and $2-4 \mathrm{~mm}$ deep are recommended to prevent the dislodgement of the 
a

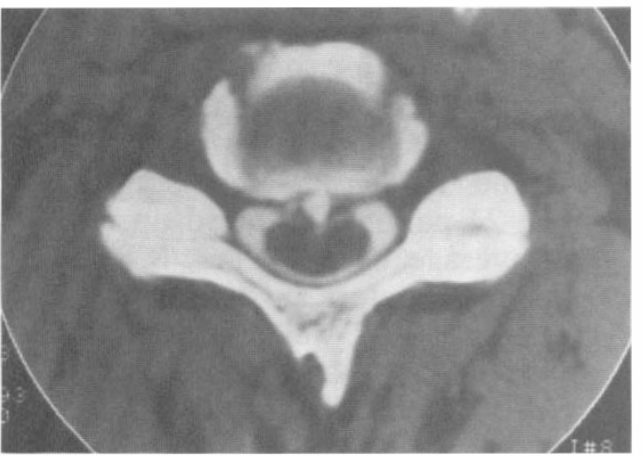

b

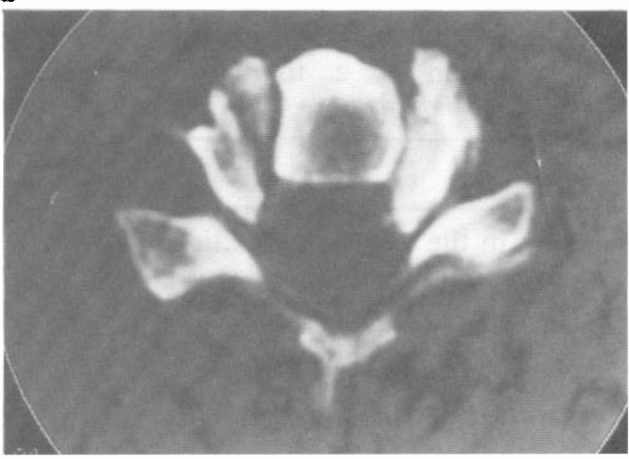

Figure 1 Computed tomography scans taken pre- and postoperatively in a 64 year old male undergoing C6 subtotal spondylectomy with fusion show excellent decompression of the ossified posterior longitudinal ligament. He achieved an $88 \%$ improvement rate. (a) Preoperative. (b) At follow up.

tricortical iliac graft anteriorly or posteriorly. A Caspar vertrebral spreader (Aesculap, Tuttlingen, Germany) permits safe distraction and extension of the space for the graft to be inserted. The dural pulsation must be observed carefully to ensure that is does not disappear during distraction; $5-8 \mathrm{~mm}$ of distraction is usually safe and sufficient for the introduction of the graft. It should be noted that the distance of the distraction depends partly on the degree of narrowing of the resected disc space(s). The iliac graft is inserted into the space and tapped gently, and then is firmly seated following the release of the distraction of the device (Fig 2). No major surgery-related complications affecting the neurological outcome were seen in the any of our patients. A sternal-occipital-mandibular immobilizer (SOMI) brace was employed for about 3-4 months postoperatively, and was discontinued when radiography revealed solid bony union. Eighteen patients underwent one-vertebra spondylectomy with fusion, 59 two-vertebra spondylectomy, and 11 three-vertebra spondylectomy. The levels decompressed and fused are shown in Figure 3. Most were operated on for C5 and C6 lesions. The length of time for solid bony union varied with bone length and quality, ranging from 12 to 25 weeks and averaging 19 weeks.

\section{Results}

Neurological outcome

Preoperative and postoperative neurological improvements are compared in Table III. About 58\% (51/88) of the patients showed moderate neurological symptoms (group B). In group A, 14 of 18 required multilevel spondylectomy; patients in groups $\mathrm{B}$ and $\mathrm{C}$ mostly underwent spondylectomy of two levels or less. The average neurological improvement rate in group $\mathrm{A}$ at the final follow up was significantly lower than for others $(p<0.01)$. Preoperative JOA scores in patients undergoing spondylectomy involving one or two vertebrae averaged $8.4 \pm 2.2$ points and, in three-vertebra resection, $7.3 \pm 3.3$ points. Patients with one- or two-vertebra spondylectomy with fusion averaged a $73.4 \%$ improvement at final follow up, while those with three-vertebra spondylectomy averaged $33.9 \%$, significantly worse $(p<0.01)$.

\section{Signal changes in MRI}

Table IV shows signal changes in the spinal cord at the decompressed levels and corresponding data on patients. In group $\mathrm{A}$, none showed normal images at

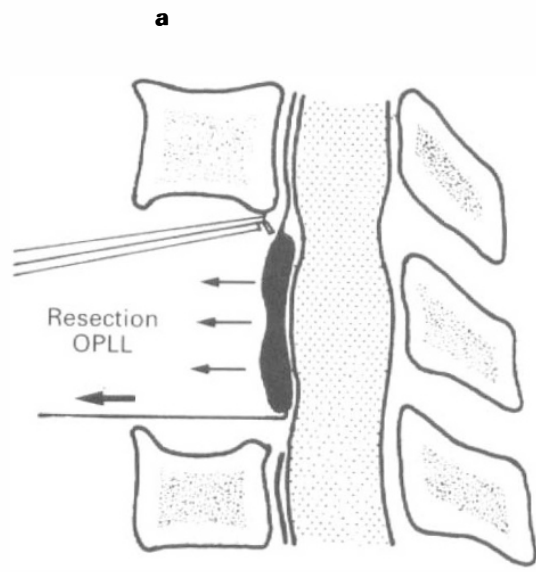

b

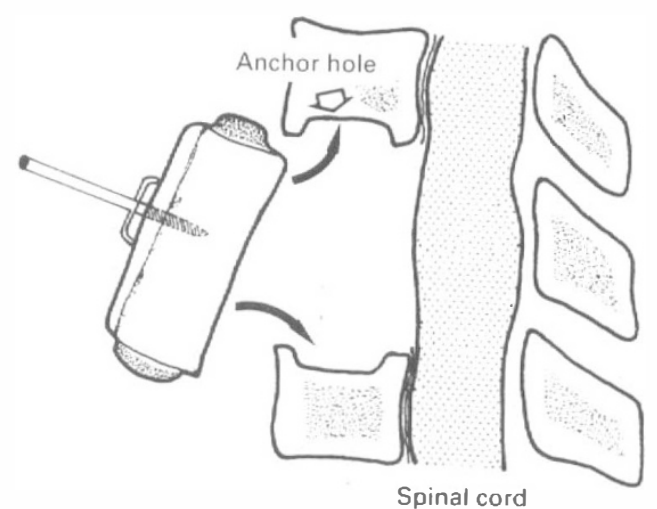

Figure 2 Operative one-vertebra spondylectomy with fusion. (a) Resection of the ossified lesion. (b) The graft is securely seated on the anchor holes made at the ends of the vertebrae above and below. 


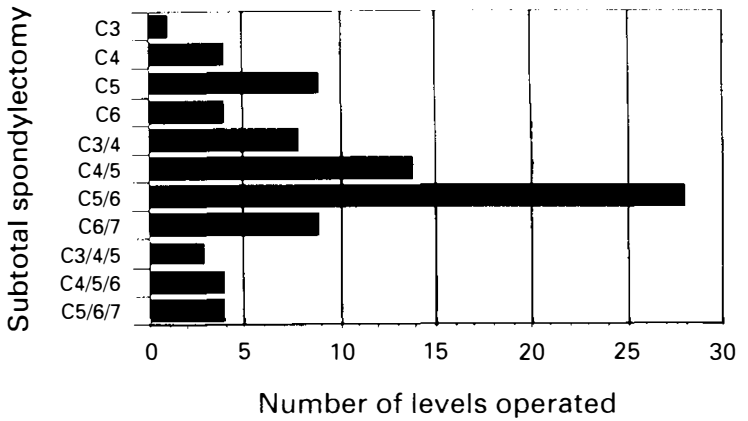

Figure 3 Vertebrae levels in subtotal spondylectomy.

follow up, although two more patients had improved findings that placed them in a slightly higher category. The average improvement in patients classified as group A was significantly poor. Group B patients showed a noticeable improvement according to MRI, where six with preoperative signals assessed as slightly high and very high demonstrated normal findings at follow up. Patients in group $\mathrm{C}$ showed almost similar findings before surgery and at follow up. No significant difference among these groups was noted in other relevant issues.

\section{Improvement in daily living levels}

In daily activities postoperatively and at final follow up (Figs 4 and 5), five patients in group A rated grade 1 or 2 preoperatively had, at follow up, improved to grade 3 but none up to grade 4 or 5 . In groups B and C, about two thirds of the patients improved at least one grade. Group A patients showed rather less improvement.

\section{Discussion}

Anterior decompression with interbody fusion is ideal for cervical OPLL myeloradiculopathy and can be superior to posterior decompression. It is essential in eliminating OPLL lesions developing anteriorly to the spinal cord and nerve roots and many authors maintain its advantage over posterior route surgery. ${ }^{22-25}$ As with osteophytectomy restricted to one or two interspaces in spondylosis, OPLL lesions can be resected, usually via subtotal spondylectomy. However, OPLL is frequently multilevel, involving three or more vertebrae. Multiple subtotal spondylectomy is technically more complex and may increase surgical risk. Laminoplasty has become the accepted treatment for multiple-level OPLL lesion. ${ }^{26,27}$ The literature, including our series with laminoplasty, ${ }^{28}$ documents an estimated $45-65 \%$ neurological improvement rate after laminoplasty. ${ }^{29,30}$ We recommend that laminoplasty be used, especially in multilevel OPLL involving the elderly or poor surgical risks, because the operation is less invasive and technically easier and rehabilitation usually proceeds without difficulty. One major limitation of this posterior procedure is that the OPLL lesion still exists after laminoplasty and may grow insidiously, constantly impinging anteriorly on neural tissue, even though the early outcome is favourable once the spinal cord migrates posteriorly. Hirabayashi et $a l^{26}$ describe later neurological deterioration in OPLL patients with laminoplasty, mostly when the ossified lesion grows anteriorly. Anterior route surgery is thus recommended and has the advantage of completely eliminating the lesion. Selection of the surgical procedure remains controversial, however, especially where multiple levels are involved.

Multiple-level ACF completely eliminates OPLL lesions, leading to neurological improvement. Epstein $^{31}$ suggested various ACF modifications based on the type and longitudinal extension of the OPLL lesion. Okada et $a l^{22}$ advocated prophylactic decompression with fusion up to the C3 vertebra to avoid superior progression of the ossified lesion, but, based on our long term radiographic observations after multiplelevel ACF, mobile interspace that does not appear to be responsible for symptoms should not be included in the fused area if subsequent mechancial overloads causing clinical instability and recurrence are to be avoided. The multiple-level ACF and three-vertebra

Table III Demographic data on patients undergoing anterior decompressive surgery

\begin{tabular}{|c|c|c|c|c|c|c|}
\hline & \multirow{2}{*}{$\begin{array}{c}\text { Number of } \\
\text { patients }\end{array}$} & \multirow{2}{*}{$\begin{array}{l}\text { Levels } \\
\text { operated }\end{array}$} & \multicolumn{3}{|c|}{ JOA points } & \multirow{2}{*}{$\begin{array}{c}\text { Average } \\
\text { improvement } \\
\text { rate }\end{array}$} \\
\hline & & & Preoperative & $\begin{array}{c}\text { 1-year } \\
\text { follow up }\end{array}$ & $\begin{array}{c}\text { Final } \\
\text { follow up }\end{array}$ & \\
\hline Group A & $\begin{array}{c}18 \\
(\mathrm{M}: 16, \mathrm{~F}: 2)\end{array}$ & $\begin{array}{ll}1-v . s .: & 4 \\
\text { 2-v.s.: } & 5 \\
3 \text {-v.s.: } & 9\end{array}$ & $4.6 \pm 0.8$ & $6.3 \pm 1.2$ & $8.8 \pm 2.1$ & $33.9 \% *$ \\
\hline Group B & $\begin{array}{c}51 \\
(\mathrm{M}: 41, \mathrm{~F}: 10)\end{array}$ & $\begin{array}{lr}\text { 1-v.s.: } & 11 \\
\text { 2-v.s.: } & 38 \\
\text { 3-v.s.: } & 2\end{array}$ & $9.3 \pm 2.4$ & $13.3 \pm 3.9$ & $15.2 \pm 1.1$ & $76.6 \%$ \\
\hline Group C & $\begin{array}{c}19 \\
(\mathrm{M}: 17, \mathrm{~F}: 2)\end{array}$ & $\begin{array}{lr}\text { 1-v.s.: } & 3 \\
\text { 2-v.s.: } & 16 \\
\text { 3-v.s.: } & 0\end{array}$ & $14.3 \pm 1.3$ & $15.2 \pm 0.6$ & $16.1 \pm 0.99$ & $66.7 \%$ \\
\hline
\end{tabular}

$\mathrm{M}=$ male, $\mathrm{F}=$ female, $-\mathrm{v} .=-$ vertebra, $\mathrm{s} .=$ spondylectomy.

${ }^{*} p<0.01$. 


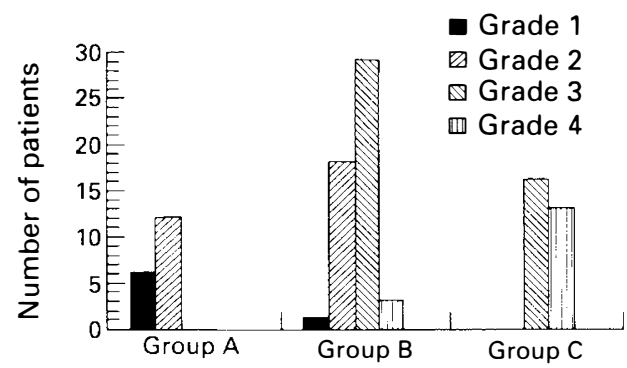

Figure 4 Preoperative daily activities.

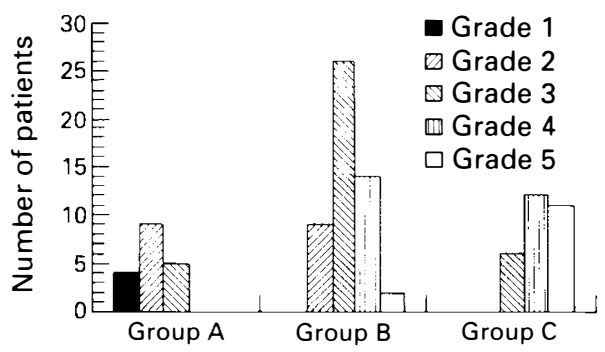

Figure 5 Daily living levels at follow up.

resection we studied resulted in unfavourable improvement, ${ }^{33}$ possibly attributable to prolonged operation time with unintended continuing anterior compression of the spinal cord. Extended ACF followed by longer bone graft in overdistraction may also cause a poorer outcome. From a spinal-cord-evoked potentials study, ${ }^{34-37}$ we found that the spinal levels truly responsible for myeloradiculopathy were mostly limited to one or two levels, even where the OPLL lesion involved three or more vertebrae. Thus, excluding ACF involving three or more vertebrae, the range of decompression appears to be limited at the most to two-vertebra spondylectomy. If decompression involving more than three vertebra levels is required, based on an evokedpotentials study, an alternative posterior procedure should be considered. Of course, where extensive laminectomy $^{38}$ results in a loss of posterior spine stability leading to possible future recurrence in mechanical damage, laminoplasty should be done. In general, posterior laminoplasty, rather than ACF, is recommended for older patients having more risk factors and showing multiple levels and more extensive OPLL involvement.

A longer duration of disease history and advanced paresis may be associated with irreversible spinal cord damage. MRI helps to detect spinal cord damage early, ${ }^{39-41}$ producing images of conditions, such as myelomalacia, contributing to poor prognosis. Postsurgical improvement is significantly affected by preoperative neurological status and, thus, repeated MRI is extremely important when observing asymptomatic OPLL patients. Neurological symptoms are often obscured in elderly patients, for example, and, if marked spinal cord compression is seen on MRI in such 
a case, earlier surgical intervention should be considered before the spinal cord becomes irreversibly damaged. In ACF attempted in patients with moderate to mild symptoms, as Sakou et al $^{42}$ noted and as we observed, the surgical outcome is superior to that by laminoplasty. Because the number of subjects examined by MRI is limited in the current study and only T1-weighted images were assessed, we could not reach any conclusion on the prognostic value of preoperative MRI; patients with better improvement, however, appeared to show a normal signal intensity at follow up.

In conclusion, we suggest that ACF warrants satisfactory neurological improvement and offers a better opportunity for improved postoperative daily activities when done earlier in the disease, resulting in the best possible long term palliation. If, however, the lesion involves more than three vertebrae, posterior decompression with extensive laminoplasty is a better alternative therapy.

\section{References}

1 Bakay L, Cares HL, Smith RJ (1970) Ossification in the region of the posterior longitudinal ligament as a cause of cervical myelopathy. J Neurol Neurosurg Psychiatry 33: 263-268.

2 Epstein NE (1992) Management of OPLL in 24 patients treated with anterior vertebrectomy and fusion versus anterior discectomy/fusion and laminectomy. J Neurosurg 76 (suppl): 375A

3 Gui L, Merlini L, Savini R, Davidovits P (1983) Cervical myelopathy due to ossification of the posterior longitudinal ligament. Ital J Orthop Traumatol 9: 269-280.

4 Klara M, McDonnell DE (1986) Ossification of the posterior longitudinal ligament in Caucasians: diagnosis and surgical intervention. Neurosurgery 19: 212-217.

5 Lecky B, Britton J (1984) Cervical myelopathy due to ossification of the posterior longitudinal ligament. J Neurol Neurosurg Psychiatry 46: $1355-1361$.

6 McAfee PC, Regan JJ, Bohlman HH (1987) Cervical cord compression from ossification of the posterior longitudinal ligament in non-Orientals. J Bone Joint Surg Br 69: 569-575.

7 Olivieri I, Trippi D, Gemignani G et al (1988) Ossification of the posterior longitudinal ligament in ankylosing spondylitis. Arthritis Rheum 31: 452.

8 Onji Y, Akiyama H, Shimomura Y et al (1967) Posterior vertebral ossification causing cervical myelopathy: a report on eighteen cases. J Bone Joint Surg Am 49: 1314-1328.

9 Rozario RA, Levine H, Stein BM (1978) Cervical myelopathy and radiculopathy secondary to ossification of the posterior longitudinal ligament. Surg Neurol 10: 17-20.

10 Satomi K, Hirabayashi K. Ossification of the posterior longitudinal ligament. In: Rothman RH, Simeone FA, (eds). The Spine. 3rd edn. Vol. 1. WB Saunders: Philadelphia, 1992, pp 639-654.

11 Tsuyama N (1984) Ossification of the posterior longitudinal ligament of the spine. Clin Orthop 184: 71-84.

12 Yu YL, Leong JCY, Fang D (1988) Cervical myelopathy due to ossification of the posterior longitudinal ligament. Brain 111: 769-783.

13 Chen WC, Chang CN, Lui TN et al (1993) Surgical treatment of ossification of the posterior longitudinal ligament of the cervical spine. Surg Neurol 41: 90-97.

14 Abe H, Tsuru M, Itoh T et al (1981) Anterior decompression for ossification of the posterior longitudinal ligament of the cervical spine. $J$ Neurosurg 55: 108-116.

15 Hanai K, Inoue Y, Kawai K et al (1982) Anterior decompression for myelopathy resulting from ossification of the posterior longitudinal ligament. J Bone Joint Surg Br 64: 561-564.

16 Hanakita J, Suwa H, Namura S et al (1994) The significance of the cervical soft disc herniation in the ossification of the posterior longitudinal ligament. Spine 19: 412-418.
17 Herkowitz HN. Cervical laminoplasty. In: Rothman RH, Simeone FA, (eds). The Spine. 3rd edn. Vol. 1. WB Saunders: Philadelphia, 1992, pp 631-638.

18 Japanese Orthopaedic Assoc (1976) Criteria on the evaluation of the treatment of cervical myelopathy. J Jpn Orthop Assoc 49: Addenda No. 12.

19 Harsh GR, Sypert GW, Weinstein PR et al (1987) Cervical spine stenosis secondary to ossification of the posterior longitudinal ligament. J Neurosurg 67: 349-357.

20 Tadao N, Taihei E, Takao E, Yuthka M (1987) Ossification of the posterior longitudinal ligament: a clinico-radiological study of 74 cases. J Neurol Neurosurg Psychiatry 50: 321-326.

21 Nose T, Egashira T, Enomoto T, Maki Y (1987) Ossification of the posterior longitudinal ligament: a clinico-radiological study of 74 cases. J Neurol Neurosurg Pychiatry 5: 321-326.

22 Okada K, Shirasaki N, Hayahsi H et al (1991) Treatment of cervical spondylotic myelopathy by enlargement of the spinal canal anteriorly followed by arthrodesis. J Bone Joint Surg Am 73: $352-364$.

23 Kamioka Y, Yamamoto H, Tani T et al (1989) Postoperative instability of cervical OPLL and cervical radiculopathy. Spine 14: $1177-1183$.

24 Kojima T, Waga S, Kubo Y et al (1989) Anterior cervical vertebrectomy and interbody fusion for multilevel spondylosis and ossification of the posterior longitudinal ligament. Neurosurgery 24: 864-872.

25 Tominaga S (1980) The effects of intervertebral fusion in patients with myelopathy due to ossification of the posterior longitudinal ligament of the cervical spine. Int Orthop 4: 183-191.

26 Hirabayashi K, Miyasaka J, Satomi K (1981) Operative results and postoperative progression of ossification among patients with ossification of cervical posterior longitudinal ligament. Spine 6: 354-464.

27 Itoh T, Tsuji H (1985) Technical improvement and results of laminoplasty for compressive myelopathy in the cervical spine. Spine 10: $729-736$.

28 Tomita K, Nomura S, Umeda S, Baba H (1988) Cervical laminoplasty to enlarge the spinal canal in multilevel ossification of the posterior longitudinal ligament with myelopathy. Arch Orthop Trauma Surg 107: 148-153.

29 Kawai S (1991) Cervical laminoplasty. In: Bridwell KH, DeWald RH, editors. The Textbook of Spinal Surgery. Vol. 2. JB Lippincott, Philadelphia: 805-812.

30 Kimura I, Oh-hama M, Shingu H (1984) Cervical myelopathy treated by canal-expansive laminaplasty. J Bone Joint Surg Am 66: 914-920.

31 Epstein N (1993) The surgical management of ossification of the posterior longitudinal ligament in 51 patients. J Spinal Disord 6: $432-455$.

32 Baba H, Furusawa N, Imura S et al (1993) Late radiographic findings after anterior cervical fusion for spondylotic myeloradiculopathy. Spine 18: 2167-2173.

33 Baba H, Furusawa N, Tanaka Y et al (1994) Anterior decompression and fusion for cervical myeloradicuopathy secondary to ossification of the posterior longitudinal ligament. Int Orthop 18: 204-209.

34 Baba H, Shima I, Tomita $\mathrm{K}$ et al. Clinical usefulness of spinal cord evoked potentials. In: Schramm J, Jones SJ, (eds). Spinal Cord Monitoring. Springer-Verlag, Berlin: Heidelberg, 1985, pp 245-249.

35 Baba H, Tomita K, Umeda S et al (1988) Clinical study of spinal-cord-evoked potentials. In: Ducker TB, Brown RH, editors. Neurophysiology and Standards of Spinal Cord Monitoring. Springer-Verlag, New York: 216-221.

36 Baba H, Kawahara N, Nagata S et al (1993) Spinal-cord-evoked potentials in cervical and thoracic myelopathy. In: Jones SJ, Boyd S, Hetreed M, Smith NNJ, editors. Handbook of Spinal Cord Monitoring. Kluer Academic, Dordrecht: 99-103.

37 Baba H, Kawahara N, Tomita K, Imura S (1993) Spinalcord-evoked potentials in cervical and thoracic myelopathy. Int Orthop 17: 82-86.

38 Nagashima C (1972) Cervical myelopathy due to ossification of the posterior longitudinal ligament. J Neurosurg 37: 653-660.

39 Luetkehans T, Coughlin B, Weinstein M (1987) Ossification of 
the posterior longitudinal ligament diagnosed by MR. AJNR 8: 924-925.

40 Takahashi M, Sakamoto Y, Miyawaki M, Busaka H (1987) Increased MRI signal intensity secondary to chronic cervical cord compression. Neuroradiology 29: 550-556.
41 Widder D (1989) MR imaging of ossification of the posterior longitudinal ligament. AJR 153: 194-195.

42 Sakou T, Miyazaki A, Tomimura K (1979) Ossification of the posterior longitudinal ligament of the cervical spine: subtotal vertebrectomy as a treatment. Clin Orthop 140: 58-65. 